\title{
GeRHARD NeWEKLOWSKY
}

\section{ZILJSKO NAREČJE NA BISTRICI IN V STRAJI VASI}

COBISS: 1.08

$\mathrm{V}$ prispevku opisujemo glavne posebnosti slovenskega ziljskega narečja v koroških občinah Bistrica na Zilji in Straja vas. V narečju najdemo prosti tonemski naglas, umik dolgega cirkumfleksa, bogat inventar naglašenih samoglasnikov, akanje $(o>a)$. Inventar nenaglašenih samoglasnikov je močno zmanjšan. Ustnika $b$ in $v$ sovpadata, mehkonebniki se palatalizirajo pred sprednjimi samoglasniki. Ohranja se slovenska morfologija, slovar je arhaičen.

Ključne besede: ziljska slovenščina, bistriški govor, sociolingvistična situacija, fonetični razvoj

\section{The Slovenian dialect of Feistritz an der Gail (Bistrica na Zilji) and Hohenthurn (Straja vas)}

This article describes the main linguistic features of the Slovenian Gail Valley dialect in the municipalities of Feistritz an der Gail (Bistrica na Zilji) and Hohenthurn (Straja vas). The dialect is characterized by free tonemic stress, a later accent shift, a rich vowel system, vowel reduction in unstressed syllables, and change of short stressed $o$ to $a$. The consonants $b$ and $v$ merge, and the velars undergo the later Slovenian palatalization. Slovenian morphology is preserved, and the lexicon is archaic.

Keywords: Gail Valley Slovenian, Bistrica subdialect, sociolinguistic situation, phonetic development

\section{BISTRIŠKO NAREČJE}

Ziljsko narečje je najbolj zahodno slovensko narečje na severni meji slovenskega jezikovnega območja. Razprostira se po koroški Ziljski dolini od Podkloštra (Arnoldstein) proti zahodu skoraj do Šmohorja (Hermagor) in proti jugu v Kanalsko dolino v Italiji in Sloveniji (Grafenauer 1905: 196; Ramovš 1935: XXXI-XXXII; prim. tudi karto Logar - Rigler 1993, ki je z dopolnili ponatisnjena v SLA 1.1: 11). Ramovš (1935, karta) je začrtal mejo proti rožanskemu narečju nekako na višini Beljaka, kar ustreza tudi opisu Paulsena (Paulsen 1935, karte) in karti Logar - Rigler 1993. V zadnjih letih sta nastali dve monografiji o ziljskem narečju, in sicer

Prispevek je bil predstavljen na simpoziju Slavistika v prostoru Alpe-Jadran: metode raziskovanja slovenskih narečij / Slawistik im Alpe-Adria-Raum: Methoden der slowenischen Dialektforschung 29. oktobra 2015 na Univerzi Alpe-Adria v Celovcu v okviru praznovanja štiridesetletnice slavistike na tej univerzi. 
Pronk 2009, ki je podal obsežen opis najbolj zahodnega govora ziljščine (Brdo in Potoče), in Neweklowsky 2013 o bistriškem narečju.

Prvo natančno razčlembo ziljskega slovenskega narečja je opravil Paulsen, ki od zahoda proti vzhodu razlikuje šest skupin govorov (Paulsen 1935: 12-15). Naša raziskava se omejuje na bistriško narečje v občinah Bistrica na Zilji (661 prebivalcev) in Straja vas (813 prebivalcev). V SLA 1 je Bistrica na Zilji opredeljena kot točka 4 . V obeh občinah znaša delež slovenskega prebivalstva okoli 8 \%. Leta 1890 je Bistrica na Zilji imela še 815 prebivalcev, Straja vas pa 1449; danes je tendenca padajoča (prim. Neweklowsky 2013: 21-22).

Vemo, da je delež slovenskega prebivalstva na Koroškem leta 1880 znašal skoraj 30 odstotkov, pri čemer je treba upoštevati, da je bila Koroška do konca prve svetovne vojne nekoliko večja kot danes. Število Slovencev se je do danes nenehno zniževalo. Zadnji podatek štetja jezikov iz leta 2001 znaša 12.554 Slovencev, kar predstavlja samo 2,4 \% koroškega prebivalstva. Klasičnega popisa prebivalstva, v katerega bi bilo vključeno tudi spraševanje po jeziku, ni več (Ibounig 2011).

\section{DOSEDANJE RAZISKAVE ZILJSKEGA IN BISTRIŠKEGA NAREČJA}

Začetek sodobnega znanstvenega opisovanja slovenskih narečij in govorov na Koroškem sega v čas ruskega slavista Izmaila Ivanoviča Sreznjevskega in koroškega Slovenca Urbana Jarnika. Sreznjevskega je ruska vlada v letih 1839-1842 poslala na raziskovalno potovanje po slovanskih deželah, večinoma v habsburški monarhiji, da bi se pripravil za stolico slovanske filologije v Harkovu, kjer je bila ena od štirih starih univerz ruskega carstva (Neweklowsky 2007). Tedaj je Sreznjevski obiskal tudi Kranjsko in Koroško. Kot vemo iz njegovih pisem materi, se je maja leta 1841 dva dni mudil na Bistrici na Zilji in v Šentjurju (danes del občine Čajna), v Možberku je obiskal tudi župnika Urbana Jarnika (Neweklowsky 1996: 25). Med svojim potovanjem je napisal prvi pregled slovenskih narečij sploh, ki ga je poslal v Rusijo, kjer je bil istega leta natisnjen (Sreznjevski 1841, posebej o ziljskem narečju str. 156-157). Med drugim ugotovlja, da se polglasnik v ziljščini pojavlja na enakih mestih kot v gorenjščini in dolenjščini (kar velja le za kratki polglasnik), omenja akanje nenaglašenih samoglasnikov, diftongizacijo dolgega $e$-ja in $o$-ja, ostanek nosnega izgovora praslovanskih nosnih samoglasnikov v treh primerih, nadalje končnico - $y$ (kar očitno pomeni sredinski samoglasnik a) imenovalnika samostalnikov ženskega spola (bukwy) in prve osebe množine v sedanjiku glagolov (damy). V konzonantizmu omenja izgovor $w$-ja, prehod $m \mathrm{v} n$ na koncu besede, izgovor »trdega $l$-ja (kar pomeni $w$ ), ohranitev $\check{c} r, d l$ in $\check{s} \check{c}$, mlajšo palatalizacijo mehkonebnih soglasnikov $k g h \mathrm{v} \check{c} j \check{s}$, iz besedotvorja navaja predpono $v y$-, v oblikoslovju končnico -e mestnika ednine samostalnikov moškega spola $\mathrm{z}$ drugo palatalizacijo in na koncu oblike pogojnika.

Kot že navedeno, je Sreznjevski obiskal Urbana Jarnika v Možberku. Mogoče je, da je Jarnik seznanil Sreznjevskega s svojim domačim govorom. Zato se 
ne čudimo, da se Jarnikov opis ziljskega narečja (Jarnik 1842: 54-56) v bistvu ujema z opisom Sreznjevskega. Pri obeh avtorjih najdemo stavek Ziljane čerstwo marnwajo (pri Sreznjevskem marwajo) 'Ziljani govorijo trdo'. Po Jarniku trdijo to Rožani, do česar pride po njegovem mnenju zaradi izgovora $v$ kot $b$. Med drugim Jarnik omenja izgovor $g$ (na mestu rožanskega $h$ ), potem $\check{s} \check{c}$, kar lahko slišimo že v zgornjem Rožu, npr. iščem, perišče, sternišče, nadalje »češko-poljske« oblike s predpono wy-namesto iz-, ki potrjujejo trdo izgovarjavo (npr. wydjelati), epentetični $d$ (šidlo, kridlo, motowidlo), nosnik v primerih vlenči, wylenči, srenča in drugih, prvo osebo množine glagola na -my (kot Sreznjevski), nato arhaizme kot končnico - $e$ v mestniku ednine (kot Sreznjevski), besede $d \log$ 'dolg' proti $d w o g$ 'dolg, krivda', sloza, končnico -i $(-y)$ posameznih samostalnikov ženskega spola (bukwy, ziby), pogojnik pomožnega glagola biti se glasi pri Jarniku bèsm, bèsi, bè; bèsva, bèsta, bèsta; bèsmy, bèste, besò. Obstaja skrajšana oblika prihodnjika neb’n, neb'š, nebè; nebua, nebta, nebta; nebmy, nebte, nebjó namesto nebóm, nebóš itd. Jasno se razlikujeta nedoločnik in namenilnik glagolov itd.

V Jarnikovih pismih Primicu in Kopitarju se omenjajo še druge posebnosti ziljščine (gl. Pronk 2007: 113-114), ki jih v prvih dveh razpravah o ziljskem narečju ni, kot npr. izguba $w$ med zadnjima samoglasnikoma ( glaa < glawa), kar ne velja za bistriški govor, švapanje ( $l>w$ pred zadnjimi samoglasniki) in alternacija ie : e, uo : o v oblikoslovju (brieg, bregu; riezh, rezhi; ruog, rogu).

Omenjenim razpravam o ziljskem narečju je treba dodati kratek članek Tineta Logarja leta 1968 o vokalizmu in akcentu vasi Potoče v zahodni Ziljski dolini, fonološki opis njenega govora (Logar 1981) in eksperimentalno-fonetično študijo Neweklowskega (1973). V slednji se ugotavlja, da fonološka opozicija tonemov obstaja, saj gre za nasprotje nizkega in visokega tona, ne pa za rastoči in padajoči tonski potek. Ziljsko gradivo najdemo tako v Thesaurusu kot tudi v SLA 1.

\section{Posebnosti SOdOBNEGA BISTRIŠKEGA GOVORA}

Bistriško narečje pozna tonemska nasprotja v naglašenih zlogih. Dolgi samoglasniki se lahko krajšajo, tako da se tonemske opozicije pojavljajo na dolgih kot tudi na kratkih samoglasnikih zunaj zadnjega zloga, npr. nízək, (ena) nìska : (ta) nïska. Vendar se zdi, da gre $\mathrm{v}$ tem primeru za fonološke različice kvantitete. V enozložnih oblikah oziroma na naglašenem zadnjem zlogu besede obstajajo kolikostna nasprotja, npr. ôk 'volk', நolik 'velik' : நəsäk 'visok', sirk 'koruza'. Nenaglašeni samoglasniki se reducirajo. Mesto naglasa ni omejeno, vsak zlog je lahko naglašen z izjemo zadnjega kratkega odprtega zloga večzložnih besednih oblik. Dolgi samoglasniki so $i$ u iə uə e o e $о$ o $a$. Kratki naglašeni samoglasniki so e ə o $a$, nenaglašeni pa $i$ u $ə$ a, pri čemer sta $i$ unastala s krnitvijo glasov ej in ow.

Sistem soglasnikov je enak v celi ziljščini (Paulsen 1935: 47; Pronk 2009:

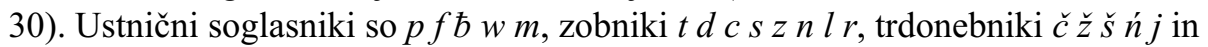
mehkonebni soglasniki $k g h$. Pozornost zbuja zvočni pripornik $\hbar$, ki se razlikuje 
od ustničnega $w$ le po močnejšem šumu; med mehkonebnimi soglasniki obstaja $g$; zvočnika $l$ (samo pred sprednjimi soglasniki) in $n$ (nikoli na koncu besedne oblike) ustrezata standardnima $l j$ in $n j$. Na koncu besedne oblike se zvenečnost soglasnikov ohranja. V pregibanju in besedotvorju obstajajo številne morfonološke alternacije glede mesta naglasa, intonacije, samoglasniške kvalitete in kvantitete. Primeri za tonemsko nasprotje: im. ed. karíta : im. mn. karîtə, im. ed. míza : or. ed. (za) mîza, im. ed. wâs : rod. mn. wás, nedoločni prid. ž. sp. bəlikka : določ. prid. balîka, nedoločnik bidata : 1 . os. ed. bîdn itd., primeri glede kolikosti, pogosto istočasno tudi kakovosti: im. ed. gräb : mestn. u grộba, nedol. kəpwátə : namenilnik kəpwät, im. ed. màs : mestn. u mệsə, nasprotja po mestu naglasa: nedol. palátə : 1. os. ed. pẹ́lan, nedol. lažátə : namenilnik lízžat, mestn. ed. (na) píača : or. ed. (pat) pəčjó itd. (podrobneje v Neweklowsky 2013: 50-54).

Najpomembnejši pojavi, ki so privedli do današnjega jezikovnega stanja, so naslednji:

Splošnoslovenski pomik naglasa tipa öko > okộ ni ohranjen, ampak je prišlo do novejšega umika, in kot rezultat najdemo ọka, sẹ́nə (s končnico -ə, ne -a), pọla, tož. ed. móža. Z notranjega zloga besede se padajoči naglas tudi umakne (bọ́lazn, prẹ́kwadə), čeprav ne vedno (poskus pojasnitve pogoja v Pronk 2011). Drugi splošnoslovenski umik s konca besede proti njenemu začetku se ohranja. Pri tem iz $e$-ja in $o$-ja nastajajo v osnovi dvoglasniki (žína, gúara) in široki samoglasniki iz praslovanskih nosnih samoglasnikov (péta, róka). Stari akut se daljša v nezadnjih zlogih (mrẹzža, pšzníca), ki se lahko potem v zaprtem zlogu skrajša (nízək: niska).

V konzonantizmu obstajajo alternacije tipa $k: \check{c}: c, s k: \check{s} \check{c}, g: j: z, g: \check{z}$, $h: \check{s}: s$, npr. ók : rod. ed. wačésa, im. ed. àpka ‘jabolko’ : im. mn. äpča, im. ed. róka : rod. daj. róčə : mestn. (nə) rócə, pridevnik ž. sp. niska : določ. m. sp. nïšča, mestn. ed. (nə) nọza : im. mn. nọja : rod. mn. núag, im. štîanža : mestn. (pa) štî̀ngah 'stopnice' (iz nemščine), im. ed. strẹha : im. mn. strîəšə idr.

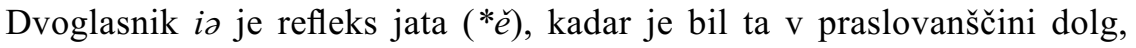
ali pa refleks cirkumflektiranega dolgega $e$-ja $(* \hat{e})$ (v tem primeru z visoko intonacijo), in nenazadnje tedaj, kadar je kratki $e$ podaljšan in naglašen zaradi slovenskega naglasnega umika (v tem primeru z nizko intonacijo), npr. snî̀g,

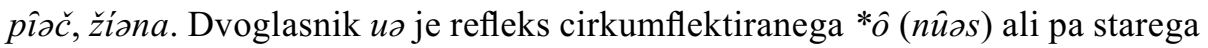
nenaglašenega kratkega $o$-ja, ki je podaljšan zaradi regresivnega slovenskega premika naglasa (z nizko intonacijo), npr. kúzza. Ozki e je refleks akutiranega jata $(* \check{e})$ in novoakutiranega $e$-ja, ozki $o$ je nastal iz novoakutiranega $o$-ja (bẹdato < věděti, lẹta < lěto, rẹzato, čẹtrt; dọbr, mọ́kar, kọža), razen tega sta $e$ in $o$ nastala iz kasneje naglašenih $e$-jev in $o$-jev kot v primerih dẹ́sat, pọ́lə, rod. ed. pọta 'plot', to pomeni po že omenjenem mlajšem premiku naglasa tipa poljệ > pọla. Refleks za dolgi polglasnik je široki $e$, ki se lahko tudi diftongira, npr. mêh, mënkatə (zaprt zlog), ந̂̀วs 'vas', kratki polglasnik preide seveda v a, npr. päs, rod. pàsa. 
Kratki naglašeni samoglasniki $e, i, u$ prehajajo - tudi $\mathrm{v}$ izposojenkah $-\mathrm{v} \partial$, npr. $t l \ddot{,}, \hbar \partial \ddot{k} k<$ nemško weg, ukə̈p. Kratki naglašeni à zadnjega ali edinega zloga je refleks kratkega $o$, izjemoma tudi $e$, npr. än $<$ on, gräb $<$ grob, dawäl $<$ dovolj, näft 'noht', päd < pod, päst < post, sträp < strop, špräs (rod. ed. špríasa) 'skuta', hräm (rod. ed. hrízma) 'hren'. Nenaglašeni o prehaja v a (karita), drugi samoglasniki pa navadno $\mathrm{v} a$, samoglasniki $e$ ě $e \mathrm{v}$ položaju po naglasu dajo a (äjstraf 'jastreb', čúəちak, dẹ́wat).

Mehkonebni soglasniki $k g h$ se palatalizirajo pred starimi samoglasniki $e, \check{e}$ in $i$, in sicer naglašenimi, nenaglašenimi, dolgimi ali kratkimi, kakor $\mathrm{v}$ osnovi tako tudi na morfemski meji, in preidejo v $\check{c} j \check{s}$, npr. čisu < kisel, na nọja < na nogě, $\check{s} i s ̌ a<h i s ̌ a$. Značilen je tudi refleks *dl (*tl ne obstaja), npr. jédwa 'jelka', bidla 'vile'; $l$ pred zadnjimi soglasniki ali pa na koncu besede $v$ prehaja $\mathrm{v} w$ (podrobnosti v Neweklowsky 2013: 62-65).

Nadalje je za bistriško narečje značilno, da prihaja pogosto do metatez soglasnika in samoglasnika oz. samoglasnika in soglasnika ali tudi do zamenjave položaja glasov, ki si ne sledijo drug za drugim, npr. nadrita (narediti), kộrəyk (okrog), cəblộwc 'Celovec', äjstraf (jastreb), நəräwc (vrabec), நučənäk, rod. நučəníka (< bowčenik < belčenik < čebelnik), slọ́za (solza), dlóg (dolg, ampak dohčas 'dol-

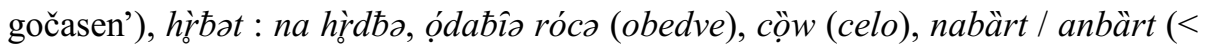
en-bart 'enkrat'), pwitja (< vpitje), hwotár (< starovisokonemško altāri, proteza $h$ je sekundarna), kôrat (Pronk 2009 ima: kộrwat < kolovrat), 1. os. sed. paldẹn (pletem), májalna (< malinje), krapíbə (koprive).

Deklinacija in konjugacija ustrezata knjižni slovenščini, vendar je treba upoštevati, da je zaradi glasovnih zakonov prišlo do zmanjšanja števila različnih končnic, kadar se končujejo na samoglasnik. Tako npr. sovpadeta končnici - $e$ in $-i,-a$ in -o, oblika miza je npr. imenovalnik, tožilnik in orodnik ednine (če zanemarimo različne toneme), miza pa je rodilnik, dajalnik in mestnik ednine. Pridevniška oblika nišč je določna oblika imenovalnika ednine in množine ter tožilnik množine moškega spola, tudi imenovalnik dvojine ženskega spola, oblika nišči (v tem primeru $i<e j$ ) je rodilnik in dajalnik ženskega spola itd. Določni in nedoločni pridevniki se jasno razlikujejo.

Nekaj značilnih besed bistriškega narečja je: črrnaw 'rdeč', smòkbəca 'rdeča jagoda', žaちaritz 'govoriti', நâratz 'vprašati, iskati', நîsswa 'lesena kuhalnica' (prim. veslo), ந̂̂waži 'pomlad' <*vy-laz (po bavarskem Auswart), čompa 'krompir', káži 'polž', kəচídlaca 'metulj', žênč 'slab, slabo' (< za nič). Nemške izposojenke so: bagôni 'hvala' < bog lonaj ('Gott lohne'), číwažən 'žica' < nemško Zieheisen (beseda se v nemščini ne uporablja več), fâncut 'flancat, krap' (bavarsko Pfanzel), grâtata 'postati, nastati' (< geraten), ilatə 'hiteti' (nemško eilen < srednjevisokonemško îlen), kâhwa 'nočna posoda' (nemško dial. Kachel), môra 'kobila' (srednjevisokonemško merha, moere, more; danes Mähre pomeni 'kljusa, mrha') itd. Romanske besede (iz furlanščine ali italijanščine) so: bäjta 'lesena bajta v planini', fáča 'isto', bäšk 'les', məgârə 'mogoče', mẹjšta 'žganec', špräs 
itd. (podrobneje v Neweklowsky 2013: 81-84, 110-174, posebej o nemških izposojenkah gl. Neweklowsky 2014; za najbolj zahodno ziljščino gl. slovar v Pronk 2009).

\section{BESEDILO}

Naslednje besedilo je prevzeto iz Neweklowsky 2013: 88-90:

\section{Sìrk}

mî smə näjpri patr̀̀galə, smə hadílə skûəz gníwa $\mathrm{z}$ na cêjna, pa püə sma tr̀̀galə u cëjna. zráwn gníbə je bíw žîə ən wäz pa kẹjn uprënžən. käkr sma hadílə pa gníbə naprệj, tว̀kə da smə püəšlə kùəńa, tüdi, da sma wûəz tudi palál, da nî buə trîəba tว̀kə djëlč nasîtə.

[Ste eden drugemu pomagali?]

sə̈ sa tûdi pamálə. pr pâwrah, čìr je buə bə̈č lədí, sə sámə dẹ́walə. pa ta bûrnə pa ệ nísə sə mûələ uzétə drùjə lûdə, tîstə sa mûələ prej lə pâwran památ jə̀tə. tìstə nî bəl tàkə.

u bëjžə sə sprázəlnə, pə pa püəšlə, püəšlə zbəčír sə pa príšlə dúplucə, da sa dúplə - žíənə, móžə - dúplucə prä smə rìəklə mî, no, da sa ga dúplə. žíənə sə sadẹ́lə na mîkənah stòlčah ku kûpca. bẹčəbärt sə žíənə dẹwalə, móžə sə ga pa bẹ́zalə. na drüjən krâjə bẹ́zalə. žîə u tə glîh šíšə, magár u zòrha, u pə̀rbən štộkə, bəl pa u ni drúji îspə tanôtrə. pa tròacə sa bẹ́čəbart nasílə kuə sìrk.

čêr je bíw bal žênč, tə̈n sə ja wsə̈ parêtə bëk str̀̀galə. mî smə ríəklə k tîstəmə tö $\mathrm{j}$ tə lẹ́dək. pa tîstəga smə pa püəšlə žìə kî, al sə mûəw, da sma ga že kî pad ürh nasílə. pa tìstəga smə pa djâlə pa tlîəh, da jə sə šûšu. no, tə lîəpəga, kär je bwo zwo lệpə, tə̈n sə parêtə - trî parêtə sa cûəl panẹlə, da sma mûələ bézatə püəšlə. tö sə štírə čûrčə ukə̈p, dwâ pa dwâ, mopa sə bệdu, da sa blï štírə ukə̈p. sáč je máw drgâčə bẹ́zu. jə̈s sñ normál knäf narẹ́du. ja, tô sma pa püəšlə drújə dên, smə ga mûələ nəsîtə gr̀̆ta pad ürh. tə̈n smə mẹ́lə tว̀čə štânžə, pa zwว̀rha tərə. pa tîstəga smə pa mûələ cẹlega zbéstə. tîst je bísu pọšlə. tö čə bwo âkl. bäl je bïw sûh, bọ́lə jə bwə.

no, prẹ́da jə snîəg pâdu, jə bowə tûdi, al se j tว̀kə pašəšîwa. bəl, käda sə ja mû səglîh snúəpə nadrítə, tàčə debíələ snúəpə. pa püəšlə sə ja mûə zə swâma, sə mûg zbézatə snäp. püəšlə tộtə snúəpə sə mûə djátə nə pêtnẹjst, dwàjstə ukə̈p jəh, pa püəšlə si mûə spët zürha kọ́li zbézatə, da nîə bîətr narâzən papíhnu, da ni pâdu (u)kòl.

tö sə pa bézalə s tọta - tu u sìrkə sə blə wə̈ščəs búčə - tötə búčujə žnûrə sə wzélə, mpa sə zbẹ́zalə zwərha kùrənk, da nî pâdu narâzno. tü jə bu sə̈ za nûcat. tə bûčə sə mẹ́lə ja kî u sìrkə tan nòtər. kə̋ sə sìrk tr̀̀gu - čòkərbart sə zaâku z nagó, pa sə pâdu na nûəs tộtə. jə tûdi príšu príəd. 


\section{Spravljanje koruze}

Mi smo najprej potrgali, smo hodili po njivi s kakšno košaro in potem smo trgali v košaro. Ob njivi je bil že en voz in konj vprežen. Kakor smo hodili po njivi naprej, tako smo potem konja tudi (vodili), da smo voz tudi peljali, da ni bilo treba tako daleč nositi.

[Ste eden drugemu pomagali?]

So si tudi pomagali. Pri kmetih, kjer je bilo več ljudi, so delali sami. Najrevnejši pa niso mogli najeti drugih ljudi, tisti so morali prej le kmetom pomagati. Tega zdaj ni več.

V veži so spraznili, potem zvečer pa so prišli duplovci, so lupili - ženske, možje - duplovci smo rekli mi prej, da so ga (sirk 'koruzo') ličkali. Ženske so sedele na majhnih stolčkih okrog kupca. Največkrat so ženske delale, moški pa so ga vezali. Na drugem kraju so vezali. Že v isti hiši, mogoče zgoraj v prvem nadstropju ali notri v kaki drugi izbi. Največkrat so koruzo nosili otroci.

Če je bil (sirk 'koruza') bolj slab, so mu vse perje ('(krovne) liste') proč potrgali. Mi smo rekli tistemu: to je ta ledik ('prost'). Tistega smo potem že kar, če si mogel, da smo ga že pod vrh nosili. Pa tega smo djali na tla, da se je sušil. Ta lepega (sirk), kar je bilo zelo lepega, tam pa so tri liste pustili zraven, da smo ga lahko potem vezali. Tu so štirje storži skupaj, dva in dva, in si vedel, da so bili štirje skupaj. Vsak je malo drugače vezal. Jaz sem navaden vozel napravil. Naslednji dan smo ga potem gor nosili, gor pod vrh. Tam smo imeli take drogove, zgoraj pod vrhom. Tistega smo morali pa vsega zvezati. Ta je potem visel, to ni bilo treba tako paziti, bolj je bil suh, bolje je bilo.

Preden je zapadel sneg, je bilo tudi, da se je tako posušilo. Ali, kadar si moral enake snope narediti, take debele snope, potem si moral s slamo zvezati snop. Nato si moral te snope dati - kakih petnajst do dvajset skupaj -, nato si jih moral spet zgoraj okrog zvezati, da ni veter narazen spihnil, da se ni zvrnil.

To so povezali s tistimi - med sirkom so bile vedno buče; te bučne vrvi so vzeli in so zvezali zgoraj okrog, da ni padlo narazen. To je bilo vse za porabiti. Te buče so imeli kar tam med koruzo. Ko si trgal sirk, kolikokrat si se z nogo zataknil in si padel na nos tja. Tudi to se je zgodilo.

\section{USODA BISTRIŠKEGA GOVORA}

Raziskava je pokazala, da stari kmečki govor obvlada danes le še majhno število ljudi, predvsem starejša generacija. Govor je soroden brško-potočkemu narečju, vendar se od njega kljub temu razlikuje. Splošna tendenca je - kot drugod v Avstriji - da se število otrok v zadnjih letih vse bolj znižuje. Občini Bistrica na Zilji in Straja vas imata skupno ljudsko šolo v Zahomcu (http://vs-hohenthurn.at, dostop 29. 1. 2016). Leta 1975/76 je bilo največ učencev, in sicer 104, od katerih jih je bilo k dvojezičnemu pouku prijavljenih 21. Leta $2013 / 14$ je šola imela samo 50 učencev, od katerih jih je bilo spet prijavljenih več k dvojezičnemu pouku, in sicer 29. Kaj to 
pomeni? Na eni strani izkazuje dejstvo, da je splošna situacija na Koroškem danes bolj naklonjena Slovencem kakor v sedemdesetih letih 20. stoletja, na drugi strani pa prijavljeni otroci večinoma niso Slovenci oziroma slovenščine niti ne govorijo in se je torej učijo kot tujega jezika (Neweklowsky 2013: 29). Jezik slovenskega pouka je knjižna slovenščina. Čeprav se bo slovenščina na Bistrici in v Straji vasi verjetno ohranila, bo stara kmečka govorica, ki smo jo opisali, čez nekaj desetletij izginila.

\section{LITERATURA}

Grafenauer 1905 = Ivan Grafenauer, Zum Accente im Gailthalerdialekte, Archiv für slavische Philologie (Berlin) 27 (1905), 195-228.

Ibounig 2011 = Peter Ibounig, Preštevanje narodnih skupnosti s pomočjo popisov prebivalstva?: podatki o občevalnem jeziku v avstrijskih popisih prebivalstva, v: Kärnten Dokumentation, Klagenfurt am Wörthersee: Amt der Kärntner Landesregierung, 2011 (Amt der Kärntner Landesregierung, Band 27), 74-82 〈http://www.volksgruppenbuero.at/images/uploads/ktn_doku_27〉, dostop 25. 1. 2016.

Jarnik 1842 = Urban Jarnik, Obraz slovenskoga narěčja u Koruškoj, Kolo: članci za literaturu, umétnost i narodni život (Zagreb) 1 (1842), 41-57.

Logar 1968 = Tine Logar, Vokalizem in akcent govora Potoč v Ziljski dolini, Zbornik Matice srpske za filologiju i lingvistiku (Novi Sad) 9 (1968), 137-143.

Logar 1981 = Tine Logar, Potoče (Potschach; OLA 146), v: Fonološki opisi srpskohrvatskih/hrvatskosrpskih, slovenačkih i makedonskih govora obuhvaćenih Opšteslovenskim lingvističkim atlasom, ur. Pavle Ivić, Sarajevo: ANUBiH, 1981 (Posebna izdanja LV, odjeljenje društvenih nauka 9), 183-191.

Logar - Rigler 1993 = Tine Logar - Jakob Rigler, Karta slovenskih narečij 1 : 500.000, Ljubljana: Geodetski zavod Slovenije, 1993.

Neweklowsky 1973 = Gerhard Neweklowsky, Slowenische Akzentstudien: akustische und linguistische Untersuchungen am Material slowenischer Mundarten aus Kärnten, Wien: Österreichische Akademie der Wissenschaften, 1973 (Schriften der Balkankommission, Linguistische Abteilung XXI).

Neweklowsky 1996 = Gerhard Neweklowsky, Ein russischer Slawist in Kärnten anno 1841, Die Brücke 22 (1996), št. 3, 22-26.

Neweklowsky 2007 = Gerhard Neweklowsky, Ismail Ivanovič Sreznevskijs Reise durch Österreich 1841-1842, Studia Slavica Hungarica (Budapest) 52 (2007), 309-318.

Neweklowsky 2013 = Gerhard Neweklowsky, Der Gailtaler slowenische Dialekt: Feistritz an der Gail / Bistrica na Zilji und Hohenthurn / Straja vas, Klagenfurt / Celovec: Drava, 2013.

Neweklowsky 2014 = Gerhard Neweklowsky, Deutsche Lehnwörter im slowenischen Dialekt von Feistritz an der Gail / Bistrica na Zilji, v: Beiträge zur interdisziplinären Slowenistik = Prispevki k meddisciplinarni slovenistiki, ur. Andreas Leben - Martina Orožen - Erik Prunč, Graz: Leykam, 2014, 173-181.

Paulsen 1935 = Viktor Paulsen, Lautlehre des slowenischen Gailtalerdialektes in Kärnten, Wien, 1935 [nenatisnjena disertacija].

Pronk 2007 = Tijmen Pronk, Gailtal Slovene in Urban Jarnik's letters to Primic and Kopitar 18111814, Slovenski jezik - Slovene Linguistic Studies 6 (2007), 111-132.

Pronk 2009 = Tijmen Pronk, The Slovene Dialect of Egg and Potschach in the Gailtal, Austria, Amsterdam - New York: Rodopi, 2009 (Studies in Slavic and General Linguistics 36).

Pronk 2011 = Tijmen Pronk, Narečje Ziljske doline in splošnoslovenski pomik cirkumfleksa, Slovenski jezik - Slovene Linguistic Studies 8 (2011), 5-17.

Ramovš 1935 = Fran Ramovš, Historična gramatika slovenskega jezika VII: dialekti, Ljubljana: Učiteljska tiskarna, 1935 (Znanstveno društvo za humanistične vede v Ljubljani, Dela 1). 
SLA 1.1-1.2 = Jožica Škofic (ur.), Slovenski lingvistični atlas 1: človek (telo, bolezni, družina) 1: atlas; 2: komentarji, Ljubljana: Založba ZRC, 2011.

Sreznjevski 1841 = Исмаил Иванович Срезневский, О наречиях славянских, Журнал министерства народного просвещения 1841, отд. II, 133-164.

Thesaurus = Thesaurus der slowenischen Volkssprache in Kärnten 1-3, ur. Erich Prunč idr.; 4, ur. Stanislaus Hafner - Ludwig Karničar; 5-7, ur. Ludwig Karničar, Wien: Österreichische Akademie der Wissenschaften, 1982-2012 (Österreichische Akademie der Wissenschaften, Schriften der Balkankommission, Sonderpublikation).

\section{SUMMARY}

\section{The Slovenian dialect of Feistritz an der Gail (Bistrica na Zilji) and Hohenthurn (Straja vas)}

Gail Valley Slovenian dialect material has been discussed since the first half of the nineteenth century, including by the Carinthian Slovenian Urban Jarnik and the Russian Izmail Ivanovich Sreznevsky, who wrote the first survey of Slovenian dialects in 1841. The article includes some data about the municipalities of Feistritz an der Gail and Hohenthurn in Carinthia, as well as a short survey of the research history. The dialect is characterized by free tonemic stress, a later accent shift towards the beginning of the word form, a rich vowel system, vowel reduction in unstressed syllables, and akanje (change of stressed $o$ into $a$ ). The consonants $b$ and $v$ merge, and the velars undergo the later Slovenian palatalization. The description is illustrated by a text about harvesting corn. The sociolinguistic situation is characterized by Slovenian-German bilingualism. There is some native-language Slovenian instruction in primary school, in which standard Slovenian is taught; the standard language is also used in church. The number of Slovenian speakers is small, and it can be assumed that this archaic dialect will disappear within the next few decades. 